\title{
A comunicação como mediação nos museus de arte
}

Ana Paula Aleixo de Moura e Souza Especialista em Gestão da Comunicação pela Escola de Comunicações e Artes da USP E-mail: anapaula.aleixo@gmail.com

"Eu vejo o futuro repetir o passado Eu vejo um museu de grandes novidades

O tempo não pára"

CAZUZA

O papel da comunicação em um museu de arte, entendida como um processo de mediação e não como um instrumento de divulgação, foi o tema do projeto de pesquisa desenvolvido no Curso de Gestão da Comunicação e realizado no Museu de Arte de São Paulo Assis Chateaubriand (Masp). Nosso objetivo foi analisar o papel da comunicação na cultura contemporânea, bem como a influência que exerce nas instituições culturais, sobretudo nos museus de arte.

O Masp, que nos últimos anos enfrenta uma situação de crise, com diminuição de exposições, de público e de investimentos, refletindo o que acontece com outros museus brasileiros, foi criado num momento de renovação das propostas para a cultura brasileira, com propósitos inovadores, voltado nitidamente a um grande público. Teve muita ascensão e por vários anos ofereceu uma programação cultural variada e intensa. Entretanto, a partir da segunda metade dos anos 1990, começou a enfrentar dificuldades financeiras, as quais só prejudicaram a sua programação cultural. Em razão disso, a crise vivenciada pelo Masp despertou nosso interesse na avaliação de como a comunicação poderia atuar a favor dessa instituição. Para tanto, foi proposto um projeto de intervenção, no qual a atuação do Gestor de Comunicação torna-se fundamental.

Este projeto preocupa-se em despertar a atenção para diversos pontos relativos à inter-relação entre comunicação e cultura, a fim de, a partir daí, apresentar possibilidades de atuação dos museus de arte na contemporaneidade.

Os museus de arte são instituições que necessitam legitimar sua atuação nos dias de hoje - época marcada por heterogeneidade cultural e contrastes sociais. Diante desse cenário, pensar a comunicação de forma estratégica e como espaço de mediação torna-se um desafio constante. O projeto de intervenção 
comunicação \& educação • Ano XII • Número 2 • maio/ago 2007

sinaliza alguns desses desafios e propõe formas de atuação, para que os museus de arte efetivamente assumam seu papel de espaço de cultura e memória.

\section{A FORMAÇÃO DO MUSEU'}

Nas décadas de 1940 e 1950, São Paulo vivia momentos decisivos do processo de industrialização, marcada pela incorporação de tecnologias mais avançadas, migrações internas e intensa urbanização. Havia apenas dois museus na cidade: o Museu Paulista (Museu do Ipiranga) e a Pinacoteca do Estado, ambos solenes e conservadores.

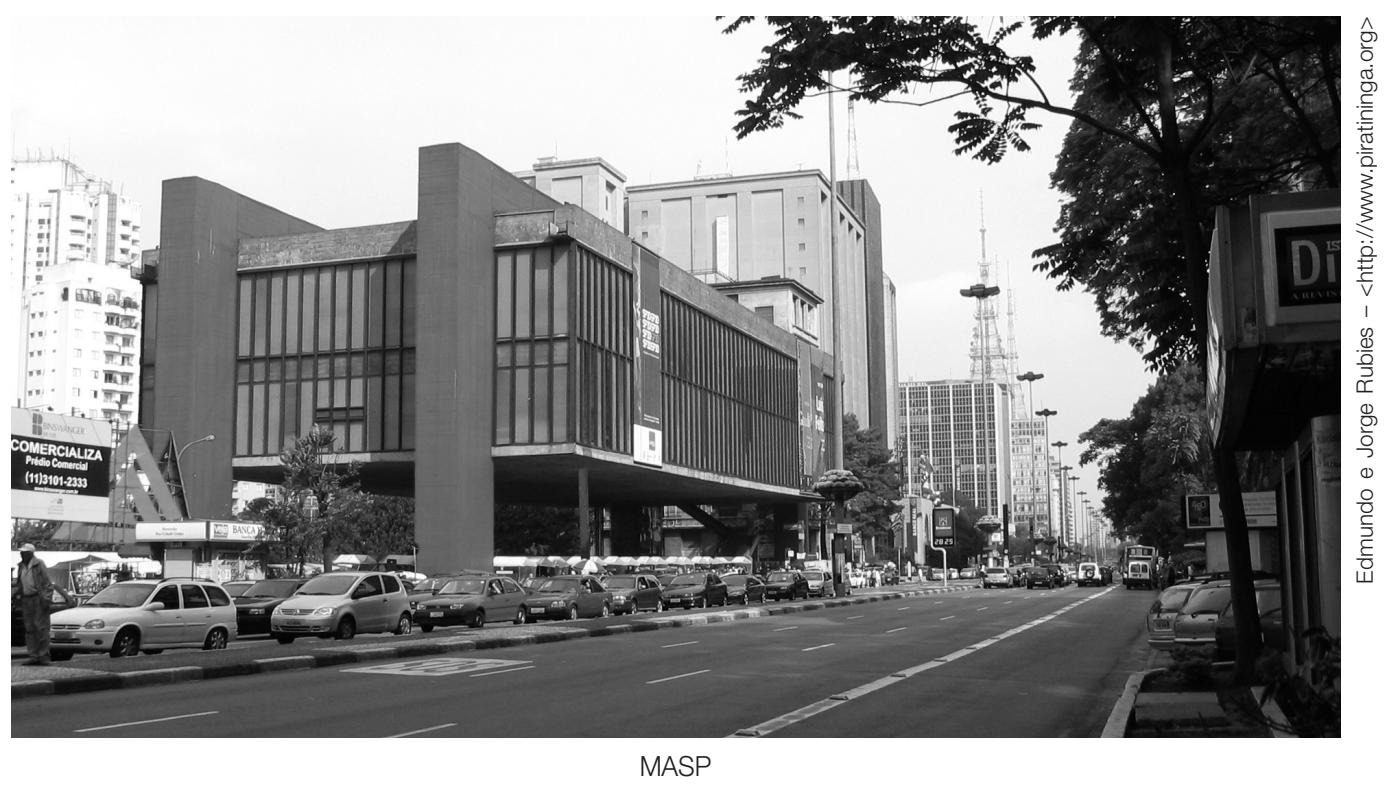

A idéia de dar ao Brasil uma das melhores galerias de arte do mundo surgiu quando Assis Chateaubriand, em visita ao Museu do Ipiranga, observou três garotos extasiados diante de um modesto quadro. Os caminhos de Pietro Maria Bardi e Assis Chateubriand cruzaram-se em 1946, ano em que Bardi e a esposa, a conhecida arquiteta Lina Bo, mudaram-se para o Brasil. Chateubriand expôs a Bardi sua intenção e convidou-o para que assumisse a direção-geral da instituição. Firmava-se aí uma parceria que duraria mais de vinte anos.

Surgia assim o Museu de Arte que, pouco tempo depois, tornou-se o Museu

1. Informações obtidas em: BARDI, Pietro M. A história do MASP São Paulo: Empresa das Artes, 1992; Página web da Fundação Assis Chateaubriand (fac.correioweb. com.br); Página web do Instituto Lina e P. M. Bardi (www.institutobardi.com. br); Página web do Museu de Arte de São Paulo As sis Chateaubriand (www. masp.art.br). de Arte de São Paulo. O primeiro endereço foi o edifício-sede dos Diários Associados, à Rua Sete de Abril. Anos depois, com a necessidade de uma nova sede, a concepção arquitetônica do museu ficou sob responsabilidade de Lina Bo. A nova sede do Masp foi inaugurada em 8 de novembro de 1968, oito anos após o início de sua construção e sem que Chateubriand pudesse assisti-la. Havia falecido sete meses antes. Na cerimônia oficial, no Auditório do Masp, um grande quadro-negro estampava a frase de Rui Barbosa a todos os convidados: "Não se pode viver dentro da civilização e fora da arte". Em 17 de dezembro 
de 2003, a sede do Museu foi tombada pelo Instituto do Patrimônio Histórico e Artístico Nacional (IPHAN).

\section{O MASP HOJE}

A coleção do Masp é considerada a mais importante no hemisfério Sul na categoria de arte ocidental, e foi tombada pelo IPHAN em 4 de dezembro de 1969. Possui cerca de 7 mil obras entre pinturas, esculturas, desenhos, gravuras, fotografias, documentos e objetos de desenho industrial, que cobrem um período de mais de 3 mil anos.

Em 1990 houve uma reestruturação administrativa e foram criadas as Coordenadorias, com a intenção de descentralizar a tomada de decisões. Entretanto, a crise econômica provocada pelo governo Collor fez com que o Museu passasse por grandes dificuldades financeiras, inclusive tendo que cancelar exposições.

Na nova fase econômica do País, a estabilidade e a baixa cotação da moeda norte-americana obtidas pelo Plano Real possibilitaram ao Masp a realização de grandes investimentos em reformas e exposições. O Projeto de Revitalização do Masp foi realizado, ininterruptamente e sem o fechamento do Museu, ao longo de mais de cinco anos, com investimentos que atingiram 20 milhões de reais. Os anos seguintes caracterizaram-se pela produção de grandes exposições - que levaram quase um milhão de pessoas a visitar o museu - e por uma mudança de estratégia junto do público visitante.

Em 2000 foi inaugurado o Masp Centro, na Galeria Prestes Maia, dirigido ao público jovem.

O Masp é regido por um Conselho Deliberativo, que indica o Presidente e membros da Diretoria. Abaixo dela encontram-se as Coordenadorias, responsáveis pela administração e execução das atividades do Museu. Possui ainda um grupo de sócios que contribui tanto financeiramente como com a doação de obras. Não há um departamento específico de comunicação - a assessoria de imprensa é terceirizada e uma agência publicitária de grande porte realiza ações pontuais. Assim, as atividades de comunicação ficam diluídas entre os departamentos. As últimas exposições realizadas foram comunicadas, prioritariamente, pela assessoria de imprensa e pelo envio de e-mails.

Atualmente as principais fontes de recursos financeiros do Museu são provenientes do setor privado, através de patrocínios, além da doação de materiais e equipamentos de empresas privadas. A Prefeitura de São Paulo é a única que contribui financeiramente - não há recursos oriundos nem do Governo Estadual nem do Federal.

\section{PROBLEMA DA PESQUISA}

Estudar o papel da comunicação em uma instituição museológica a partir da realidade do maior e mais importante museu de São Paulo torna-se relevante 
comunicação \& educação • Ano XII • Número 2 • maio/ago 2007

2. Conhecimento, por parte de um indivíduo ou grupo, que the permite situar uma obra qualquer em seu contexto próprio (TEIXEIRA COELHO. Dicionário crítico de política cultural. São Paulo: Iluminuras, 1997).

3. HALL, Stuart. A identidade cultural na pósmodernidade. 8. ed. Rio de Janeiro: DP\&A, 2003 Trad. Tomaz T. Silva e Guacira L. Louro.

4. CANCLINI, Nestor G. Culturas híbridas: estratégias para entrar e sair da modernidade. São Paulo: Edusp, 2003. p. 69. Trad. Heloísa Pezza Cintrão, Ana Regina Lessa. não só para o próprio museu, mas para o campo cultural. Assim, o objeto de investigação do projeto foi a comunicação no museu de arte, em suas diversas instâncias com seu interlocutor, e o problema-foco: Que papel a comunicação deve ter em um museu de arte, para ser entendida como um processo de mediação e não como um instrumento de divulgação?

São muitos os aspectos que permeiam a questão da comunicação do museu com seu público, de uma forma que transcende a mera divulgação de suas atividades e passa a exigir que ela seja vista como um espaço de diálogo, em que se considerem as condições socioculturais para o entendimento do museu por parte dos mais variados públicos. Tal complexidade e amplitude da relação entre o campo da comunicação e o campo da cultura, mais especificamente de um museu, faz com que seja necessário enquadrarmos alguns objetivos de acordo com temas a serem estudados:

- A comunicação nos museus de arte - Compreender como a comunicação é entendida pelos administradores dos museus de arte e como se efetiva na prática.

- Identidade cultural - Analisar como os processos comunicacionais podem intervir na legitimação do museu enquanto espaço de identidade cultural para diversos e variados públicos.

- A recepção do público - Analisar de que maneira os processos de comunicação são realizados no sentido de favorecer a fruição e recepção estética e histórica por parte do público em uma exposição de arte, independentemente de seu repertório e "competência artística"2.

A partir da contribuição teórica de Hall ${ }^{3}$, podemos afirmar que em tempos de globalização, onde o novo é priorizado, identidades são reformuladas e novas formas de representação cultural são construídas, o museu não é entendido como uma instituição capaz de se adequar às mudanças, sendo visto, assim, como um espaço tradicionalista e que guarda o antigo (especialmente os museus cujos acervos são tradicionais, como o Masp). O museu, assim, não é considerado espaço de memória e de identidade na época contemporânea, sobretudo para a grande parcela da população que não tem por hábito freqüentá-lo.

Já relacionando ao pensamento de Canclini ${ }^{4}$, podemos supor que os museus ainda se vêem dominados pelos padrões europeus e americanos, e não buscam uma identidade própria às instituições culturais latino-americanas.

O problema-foco de nossa pesquisa foi definido com base na comunicação dos museus de arte com seu público, a partir da realidade do Masp. Assim, foi necessário investigar como a comunicação vem sendo utilizada e de que forma poderia ser mais bem desenvolvida. Para isso, foram utilizadas diferentes metodologias de pesquisa, privilegiando-se os métodos qualitativos, os quais nos permitem uma apreensão mais profunda do objeto investigado. Identificamos como sendo dois os principais agentes: o público usuário (ou não) do museu e os administradores dessa instituição. A seleção da amostra segue critérios não-estatísticos e, portanto, os resultados não poderão ser generalizados para 
todo e qualquer museu. O que nos interessa, entretanto, é revelar detalhes que uma abordagem quantitativa e estatística não faria.

Além da amostra, esse processo de investigação também teve um corpus composto de textos, matérias, livros e outros materiais, cujos conteúdos nos permitiram complementar as informações obtidas de nossa amostra.

Neste trabalho, utilizamos ainda um método de observação indireta, por meio de entrevista em profundidade. Além do Museu de Arte de São Paulo, selecionamos dois outros museus de arte da capital para embasarmos nossa investigação - o Museu de Arte Contemporânea da Universidade de São Paulo (MAC-USP) e a Pinacoteca do Estado de São Paulo. A razão é a relevância dessas instituições no cenário cultural da cidade e, também, sua proposta de aproximação da população em geral, e não somente de seu público tradicional e costumeiro.

Com relação à seleção das pessoas entrevistadas, demos prioridade aos profissionais responsáveis pela comunicação no museu. As entrevistas foram realizadas pela pesquisadora e, sempre que possível, gravadas. Avaliou-se o conteúdo expresso pelo entrevistado, buscando, de forma objetiva e sistemática, encontrar elementos convergentes. A análise foi organizada com base nos temas apresentados no roteiro da entrevista.

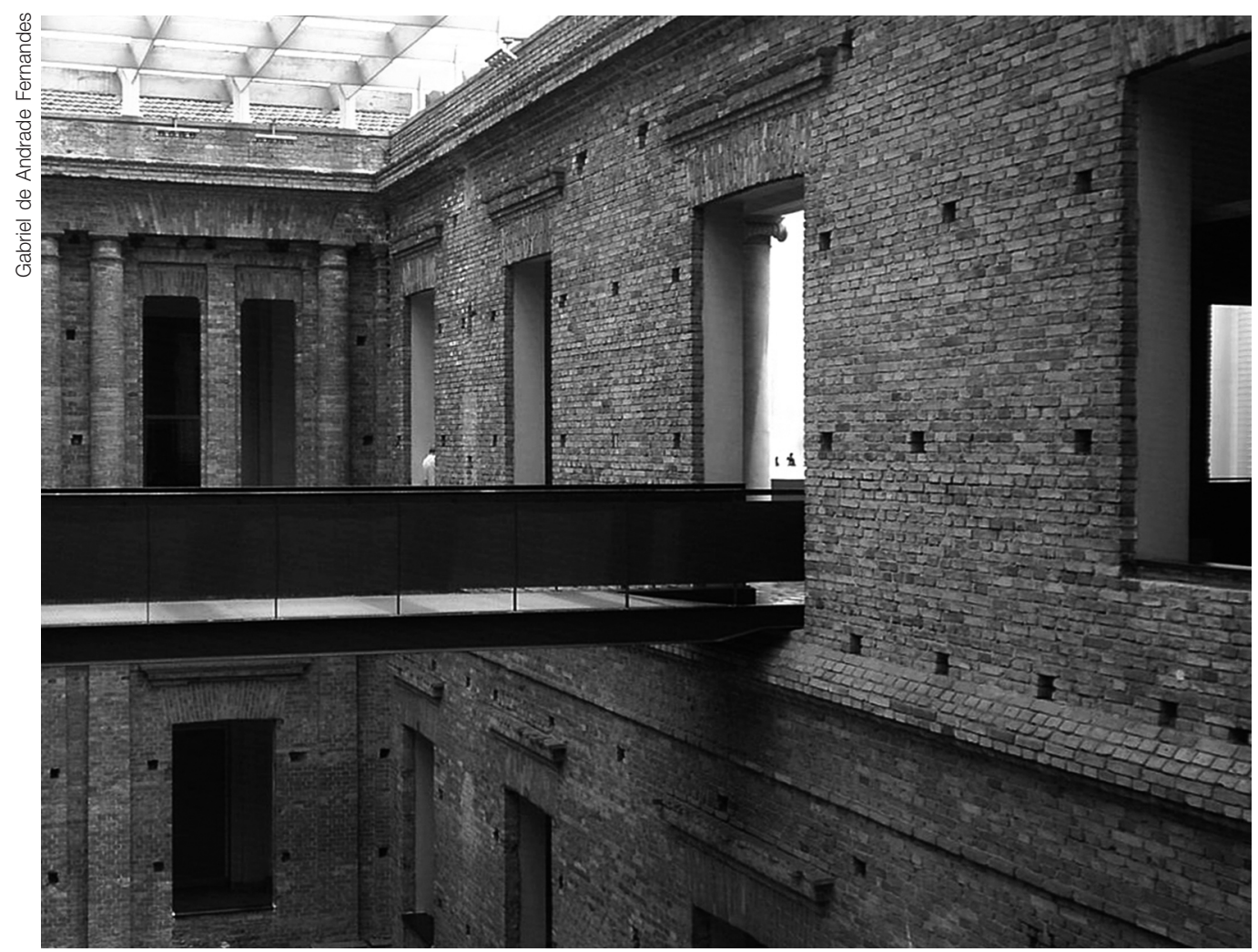

Interior da Pinacoteca do Estado de São Paulo 
comunicação \& educação • Ano XII • Número 2 • maio/ago 2007

\section{ROTEIRO DA ENTREVISTA}

- Como o Museu compreende o papel da comunicação em sua atuação?

- Quais as atribuições do departamento ou do responsável pela comunicação. Como as estratégias e atividades são planejadas?

- Quais são os agentes externos que realizam ações de comunicação (assessoria de imprensa, agência de publicidade, agência de eventos). Como se dá essa relação?

- Com relação aos seguintes instrumentos de comunicação:

- telemarketing

- website

- mailing list

- periódicos/revistas

- folders

- convites para exposições

- guias de visitação

- materiais educativos

- catálogos

- legendas/textos explicativos (de parede)

- outros materiais de divulgação das atividades, todos eles são realizados no Museu? Por quem e como?

- Quem faz e como se realizam os projetos de cenografia/museografia para as exposições? Existe a participação de outros departamentos do museu no momento da concepção museográfica?

- Como é a relação entre o departamento de Ação Educativa e as áreas de comunicação e cenografia (existem ações planejadas e realizadas em conjunto)?

- Como o Museu classifica seu público?

- Existem ações de avaliação entre o público? Se existe, como são feitas?

- Há uma Associação de Amigos do Museu?

- Que pontos relativos à comunicação o Museu considera que estão funcionando. Quais gostaria que melhorassem ou fossem introduzidos à prática do Museu?

De maneira geral, os museus compreendem a importância da comunicação em seu trabalho; entretanto, na maioria das vezes ela ainda é praticada de maneira instrumental e pontual. A área ou o profissional de Comunicação é responsável por prestar serviços de divulgação aos outros departamentos e por comunicar externamente as atividades e serviços do museu. Pudemos notar o uso constante dos termos visibilidade e divulgação, atrelados ao conceito de comunicação dos museus.

É possível também perceber, especialmente nos casos do MAC e do Masp, que a idéia de comunicação expressa pelo profissional responsável distancia-se da idéia de comunicação efetivamente praticada e pregada pelas diretorias das instituições. Não houve referências por parte dos profissionais dos museus 
quanto ao papel integrador e mediador da comunicação, e que pode promover não só a atração dos visitantes, como configurar o museu como um espaço de produção e compartilhamento de significados.

De acordo com Martín-Barbero, "mediação significa que entre estímulo e resposta há um espesso espaço de crenças, costumes, sonhos, medos, tudo o que configura a cultura cotidiana" ${ }^{\prime \prime}$. É por conta disso que pensamos a comunicação como um processo de mediação, capaz de criar um canal de diálogo em que museu e público passem por um processo de transformação.

Se considerarmos que os museus, atualmente, têm o desafio de repensar suas estratégias de apresentação ao público, concluímos que também devem pensar em novas possibilidades de mediação, diferentes das tradicionalmente realizadas, levando em conta a heterogeneidade cultural e as contradições sociais de seu público. Para que isso ocorra, é necessário haver uma modificação no conceito de comunicação, de forma que esta não mais seja vista como uma ferramenta de divulgação, e sim como um espaço que permeia todas as relações existentes interna e externamente, desde a concepção das exposições, passando pelo conhecimento de seu interlocutor e pelas formas adotadas de mediação entre obra/instituição e público.

\section{PROJETO DE INTERVENÇÃO}

Conforme mencionado na introdução deste trabalho, as propostas apresentadas sinalizam algumas possibilidades de atuação dos museus diante do cenário cultural contemporâneo. Pensando no Museu de Arte de São Paulo, nosso principal objeto de estudos, propomos uma série de intervenções no sentido de repensar sua atuação e sugerir modificações.

Profissionalizar a comunicação - As ações de comunicação são realizadas de forma diluída entre os departamentos. A Coordenadoria de Atendimento e Informática é responsável por parte delas, mas não há nenhuma integração com ações feitas pelas outras coordenadorias. É necessário que haja uma área/divisão exclusiva para a comunicação.

Integrar a atuação da comunicação com as demais áreas - A área de comunicação não pode ser vista como suporte ou unidade de apoio, e sim deve participar do processo de decisão em relação à programação de exposições, atividades e outros serviços dentro do museu, bem como da elaboração dos materiais das outras áreas.

Aproximar-se dos agentes terceirizados - Especialmente com relação à agência de publicidade, é fundamental um trabalho mais próximo e integrado à realidade e aos propósitos do museu. Muitas vezes os conteúdos dos anúncios publicitários poderiam ser mais bem trabalhados se houvesse a participação direta do profissional de comunicação.

Promover maior integração entre as áreas de Comunicação, Ação Educativa e Curadoria/Museografia - Este ponto é fundamental para que sejam realizadas
5. MARTÍN-BARBERO, Jesús, apud SOARES Ismar. A inter-relação Comunicação-Educação. Mimeo. 
comunicação \& educação • Ano XII • Número 2 • maio/ago 2007

6. GRINSPUM, Denise. Educação para o patrimônio: museu e escola - Responsabilidade compartilhada na formação de públicos. 2000. Tese (Doutorado em Educação)- Faculdade de Educação, Universidade de São Paulo, São Paulo, 2000.

7. CHAGAS, Mario. Cultura, patrimônio e memória. Revista Museu. Disponível em: <http:// www.revistamuseu.com. br>. Acesso em: 10 maio 2005. exposições capazes de equilibrar estética e informação, espetáculo e conteúdo. A exposição, sendo ela mesma uma forma de comunicação, deve respeitar a diversidade e heterogeneidade do público. Não pode digerir conteúdos para diferentes públicos, mas sim criar canais de diálogo com eles, utilizar diferentes níveis de linguagem para se comunicar. Daí a importância do trabalho de proximidade entre as áreas de Educação, Comunicação e Museografia.

Especialmente a relação entre comunicação e educação merece prioridade - Uma vez que o trabalho da ação educativa objetiva a formação de público, uma maior integração à área de comunicação possibilitaria ao Museu estender seu trabalho a novos públicos.

Considerando a importância de realizar um trabalho que não se limite à escola, mas que se volte à família ou comunidade ${ }^{6}$, propomos: ações facilitadoras para o retorno dos alunos com seus pais (descontos ou convites), programação de atividades ligadas à família, cursos dirigidos aos pais e parcerias com entidades dedicadas à educação de adultos, programa de atividades direcionado a líderes comunitários e organizações civis dedicadas ao trabalho entre a população carente.

Conhecer o público - Para que possa realizar estratégias de mediação com os diferentes públicos, é necessário que o museu conheça, principalmente, aqueles que normalmente não passam por um pré-cadastramento. O Masp tem uma localização privilegiada, onde circulam milhares de pessoas por dia. O que pensam do Museu? Se já o visitaram, que fatores foram motivadores? Se não visitaram, por que não o fizeram? Estas são apenas algumas das questões que subsidiarão o Museu de informações fundamentais para que possa repensar sua atuação.

Aproximar-se de universidades e agências de fomento - Um dos motivos apontados para a ausência de pesquisas de público é a falta de profissionais para realizá-las. Aproximar-se mais das universidades, para um trabalho em conjunto, gera uma forma de comunicação e leitura permanente do acervo e das exposições realizadas. Em todos os museus entrevistados foi mencionado o interesse de estudantes e professores universitários em realizar pesquisas. É possível aproveitar essa busca natural para que sejam feitas ações conjuntas, sobretudo para investigar com mais freqüência os processos de recepção e reavaliar as atividades.

Assumir seu papel de espaço de cultura e memória - Quando mencionamos o termo espaço de cultura, não nos referimos ao sentido físico, e que denomina comumente centros ou casas voltados a atividades artísticas e culturais variadas, mas ao sentido de espaço de preservação da memória, de produção e compartilhamento de significados, de identidade cultural. Ressaltamos que a preservação da memória não se limita à conservação dos testemunhos materiais (obras), pois a memória "situa-se na relação entre o sujeito e o objeto de memorização" que o Museu deve assumir a sua função pública, resgatando a diretriz proposta por P. M. Bardi, de museu vivo. Para isso, deve se voltar para a comunidade, abrir-se não só fisicamente, mas também em termos de conteúdo. As atividades realizadas pelo Serviço Educativo já apontam nessa direção, mas é necessário 
ampliá-las a outros grupos, como entidades sociais, sindicatos, comitês etc., como forma de o Museu não ser mais um espaço de legitimação e identidade apenas para a cultura de elite. Uma ação importante é a facilitação do acesso do público de menor poder aquisitivo por meio do barateamento do ingresso. $\mathrm{O}$ incentivo pode ocorrer em um dia específico para não comprometer a sustentabilidade financeira da instituição, mas deve coincidir com os dias de folga da maior parte da população, portanto, sábado ou domingo.

Estreitar o laço entre os museus - É fundamental a formação de uma rede de museus, para potencializar sua atuação de forma integrada. Poderia ser constituída através de um comitê permanente dos museus da cidade de São Paulo, com o objetivo de organizar calendários, realizar ações conjuntas (mostras, circuitos), publicações e até mesmo pesquisas em parceria. O Museu também poderia aproximar-se de outras entidades culturais, como grupos de teatro, orquestras, corais etc., visando à realização de programações que apresentassem linguagens artísticas variadas, porém com um mesmo tema. Com isso, haveria o fortalecimento dos laços institucionais do Masp dentro do setor cultural, bem como a sua aproximação a novos públicos.

\section{O GESTOR E OS ESPAÇOS DA COMUNICAÇÃO}

Defendemos que a comunicação no Museu tem que ser pensada como um processo de mediação. Deve haver, portanto, um trabalho não só voltado a ações pontuais e operacionais, mas também que pense o espaço comunicativo do Museu de forma contínua e integrada. Quando falamos de espaço comunicativo, não nos limitamos a processos somente de emissão e recepção, conforme nos aponta Baccega: "para os estudos e a prática dos processos comunicacionais, nem só a emissão, nem só a recepção: o homem vive e se forma na práxis, da qual é parte integrante"

Portanto, consideramos que a atuação do Gestor dentro do Museu deve abranger todos os processos de comunicação que constituem o espaço museológico - comunicação externa, acolhimento do visitante, cenografia/museografia, instrumentos de mediação -, ou seja, todas as possibilidades de diálogo que o público terá com a instituição. O Gestor de Comunicação no Museu deve abrir tantas possibilidades de diálogo com o público quantas forem possíveis. O público deve perceber que tem vez e voz dentro do ambiente museológico, para que não se sinta intimidado ou oprimido pela eventual falta de repertório e competência artística. Estes mecanismos de diálogo precisam ser constantes, não se restringindo a exposições temporárias ou eventos isolados, como forma de conscientizar o público de que o Museu é um patrimônio que lhe pertence, e não um ambiente alheio e distante de sua realidade.
8. BACCEGA, Maria Aparecida. O gestor e o campo da comunicação. In: BACCEGA, Maria Aparecida (Org.). Gestão de processos comunicacionais. São Paulo: Atlas 2002. 


\section{comunicação \& educação • Ano XII • Número 2 • maio/ago 2007}

Resumo: O trabalho apresenta uma análise sobre a comunicação nos museus de arte na contemporaneidade, a partir do estudo do Museu de Arte de São Paulo. Tem por objetivo propor estratégias de atuação para que essa instituição legitime-se como espaço de cultura e memória na atualidade, considerando os processos comunicacionais que aí se constituem.

Palavras-chave: cultura, artes, comunicação, mediação, museus, Masp.
Abstract: This document presents a discussion regarding the Communication in the Arts Museums, in the contemporaneity, based on the study of the São Paulo Museum of Art. It aims to propose strategies for this museum to legimate itself as an space of culture and memory in the present time, considering the communication process that involve this cultural institution.

Keywords: culture, arts, communication, mediation, Masp. 